\title{
MUDANÇAS NO USO E OCUPAÇÃO DO SOLO EM MICROBACIA URBANA E PROCESSOS EROSIVOS: UMA ANÁLISE MULTITEMPORAL
}

\author{
Maria Luiza Appoloni Zambom ${ }^{(a)}$, Thiago Augusto de Paula Pepe ${ }^{(b)}$, Marcilene Dantas-Ferreira ${ }^{(c)}$ \\ ${ }^{(a)}$ Departamento de Ciências Ambientais, Universidade Federal de São Carlos, E-mail:ma_lu_zambom@hotmail.com \\ (b) Departamento de Ciências Ambientais, Pontifícia UniversidadeCatólica de Minas Gerais (PUC Minas), E-mail: \\ thiago_pepe@hotmail.com \\ (c) Departamento de Engenharia Civil, Universidade Federal de São Carlos, E-mail: $\underline{\text { mdantas@ ufscar.br }}$
}

Eixo: Uso e ocupação das terras e legislação ambiental

\begin{abstract}
Resumo
Os processos erosivos em uma dada região representam uma condição ambiental básica e fundamental para realização de projetos que vão desde planos diretores até o parcelamento do solo. Portanto, o objetivo deste trabalho é comparar os processos erosivos existentes no Parque Ecológico da Água do Camargo no período de 2004 a 2015 e relacionar os dados obtidos com as mudanças de uso e ocupação do solo ocorridas na microbacia. Assim, utilizando-se o software gratuito QuantumGis versão 2.18 e as imagens disponíveis no Google Earth Pro (2004 e 2015), foi gerada inicialmente a carta de delimitação da microbacia, de uso e ocupação do solo e de inventário de processos erosivos para os respectivos anos. Dessa forma, a partir da análise multitemporal realizada, foi possível demonstrar a relação direta entre a evolução do processo erosivo da área e o aumento das áreas urbanizadas na microbacia de estudo.
\end{abstract}

Palavras chave: Erosão; Área urbana; Avaré.

\section{Introdução}

A erosão pode ser definida como um processo de desgaste da superfície terrestre pela ação do intemperismo, sendo a mesma, inerente da dinâmica geomorfológica da Terra. No contexto urbano, porém, ela pode ser o foco de grandes problemas para o poder público e a população. Segundo Almeida Filho (2000), no Brasil esse tipo de degradação do solo gera um grande ônus para a sociedade com a perda de solos agricultáveis, a necessidade de grandes investimentos em obras públicas para frear o processo erosivo que esteja gerando riscos de deslizamento de terras, além do comprometimento que causa à disponibilidade de recursos hídricos com o assoreamento de rios e córregos.

Dois fatores igualmente decisivos que desencadeiam os processos erosivos são o tipo de solo e as características pluviométricas de determinada região. Assim, caso o solo apresente condições suscetíveis, a chuva certamente conduzirá à formação da erosão (ALMEIDA FILHO, 2000). Isto posto, faz-se importante no contexto deste trabalho, trazer informações sobre a formação geológica do Município de 
Avaré. Um importante instrumento utilizado como base para este estudo é o Relatório Técnico Final chamado "DIAGNÓSTICO DOS PROCESSOS DE EROSÃO NA ÁREA URBANA DO MUNICÍPIO DE AVARÉ-SP”, do Instituto de Pesquisas Tecnológicas do Estado de São Paulo - IPT, datado do mês de novembro de 2015 .

Segundo o referido relatório, com relação à geologia, em Avaré predominam rochas da Formação Pirambóia, do Grupo São Bento (formações Botucatu e Serra Geral) e do Grupo Botucatu. Ocorrem, subordinadamente, depósitos Aluvionares associados às principais drenagens. Predominam na Formação Pirambóia os arenitos quartzosos (cores esbranquiçadas a avermelhadas). A granulometria é considerada de média a muito fina, com até $20 \%$ de matriz argilosa. A estratificação é considerada plano-paralela, cruzada planar, tangencial na base e acanalala (raramente).

A Formação Vale do Rio do Peixe ocorre na porção noroeste do município. Predominam arenitos muito finos a finos, de cores marrom-claro, rosado a alaranjado, de seleção moderada a boa, com intercalações de siltitos de cores creme a marrom. Os arenitos formam estratos tabulares de aspecto maciço, com zonas de estratificação plano-paralela grosseira e estratos também tabulares, com estratificação cruzada tabular a acanalada, em geral de médio a pequeno porte. Os estratos lamíticos são em geral arenosos, maciços ou com estratificação mal definida. Localmente ocorrem pequenos corpos lenticulares de arenito conglomerático, com estratificação cruzada de pequeno porte. Os Sedimentos Aluvionares/DepósitosAluvionares estão representados por aluviões em geral, incluindo areias inconsolidadas de granulação variável, argilas, silte e cascalheiras fluviais subordinadamente, em depósitos de calhas e/ou terraços e, localmente, turfa.

No município de Avaré, os processos erosivos lineares são importantes. Segundo o referido Relatório Técnico (IPT, 2015), durante o trabalho de cadastramento dos processos erosivos urbanos e durante as vistorias de campo, constataram-se diferentes situações que ofereciam, aparentemente, maior ou menor risco ao meio urbano. Esta constatação trouxe então a necessidade da elaboração de uma análise capaz de hierarquizar as erosões para priorizar as ações de estabilização ou recuperação desses processos. Ao final do estudo, foram detectados 12 pontos de erosões urbanas, sendo 3 de alta criticidade, 4 consideradas média e 5 no grau correspondente a baixa. Dentre as três erosões altamente críticas, a primeira é a existente no Parque Ecológicoda Água do Camargo Prof. ${ }^{a}$ Terezinha Teixeira de Freitas. Segundo o documento, a erosão principal e seus ramos encontram-se em processo de evolução e podem atingir a curto/médio prazo a infraestrutura urbana existente no seu entorno (viário, redes de água e esgoto, moradias etc.). 
A reserva foi criada pela Lei Ordinária $\mathrm{N}^{\circ}$ 53, de 25 de abril de 2001 como uma área protegida do município da Estância Turística de Avaré, com as seguintes finalidades: proteção ao ambiente natural, desenvolvimento de atividades educacionais, culturais e de recreação (AVARÉ, 2001). No entanto, nunca tendo servido a estes fins, há mais de uma década, o local é alvo de denúncias e de inquérito civil público imposto pelo Ministério Público Estadual à Prefeitura Municipal devido à existência e evolução de erosão urbana em seu território.

A conclusão apontada pelo Relatório Técnico do IPT vincula a evolução dos processos erosivos do Parque ao aumento da urbanização do seu entorno, ressalta também os prejuízos financeiros e os impactos ambientais resultantes destas problemáticas, bem como a necessidade de resoluções advindas de ações por parte dos gestores públicos. Este estudo visa fornecer subsídio para um melhor entendimento sobre evolução das erosões e sua relação com o uso e ocupação do solo na microbacia, no qual será preponderante para tomada de decisão no intuito de solucionar o problema, além de direcionar as discussões no âmbito do zoneamento urbano ambiental para que se evite novos problemas deste tipo no município.

Este trabalho tem como principal objetivo comparar os processos erosivos existentes no Parque Ecológico

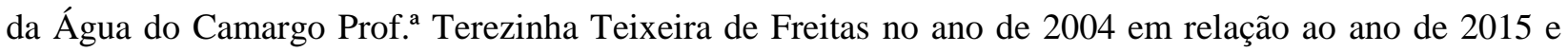
relacionar os dados obtidos com as mudanças de uso e ocupação do solo ocorridas na microbacia do Córrego Água do Camargo no mesmo período, como forma de oferecer subsídios na tomada de decisão no âmbito do planejamento ambiental da cidade de Avaré-SP.

\section{2. Área de Estudo}

Localizada na região sudoeste do Estado de São Paulo à latitude $23^{\circ} 05^{\prime}$ '55"S, longitude $48^{\circ} 55^{\prime} 33^{\prime \prime}$ W e altitude de 780 metros, o município da Estância Turística de Avaré-SP conta com uma área territorial total de aproximadamente 1.213,055 $\mathrm{km}^{2}$ (IBGE, 2010), que engloba as Bacias Hidrográficas do Alto Paranapanema e do Médio Paranapanema. Segundo a classificação climática de Koeppen, o clima predominante é o chamado Tropical de Altitude (Cwa), apresentando o valor total para a precipitação anual de 1.388,1 milímetros, variando entre o mínimo de 40,9 mm e máximo de 213,1 mm (Cepagri Unicamp).

O primeiro e mais importante objeto a ser definido nesse estudo refere-se à área total do Parque Terezinha de Freitas. Isto foi feito, portanto, a partir de imagens de satélite do software Google Earth Pro trabalhadas no QuantumGIS, e os vértices de limite da área existentes em arquivo fornecido pela Secretaria Municipal de Meio Ambiente de Avaré. Como componente hídrico essencial da área do Parque Terezinha de Freitas, 


\section{OS DESAFIOS DA GEOGRAFIA FÍSICA NA FRONTEIRA DO CONHECIMENTO \\ Instituto de Geociências - Unicamp \\ Campinas - SP \\ 28 de Junho à 02 de Julho de 2017}

o Córrego do Camargo nasce dentro dos limites da área protegida e seu curso percorre-a transversalmente.

A partir de dados primários obtidos em campo, foram georreferenciadas suas nascentes e seu curso principal, utilizando-se o equipamento GPS de Navegação Garmin GPSMAP modelo 64s. Utilizou-se dados geográficos da Empresa Brasileira de Pesquisa Agropecuária - EMBRAPA - Brasil em Relevo para definir a MicrobaciaHidrográfica a partir da técnica de hispometria (representação da elevação de um terreno através das cores).As Figuras1 e 2 abaixo ilustram a área do Parque e a microbacia hidrográfica referida, onde o mesmo se encontra.

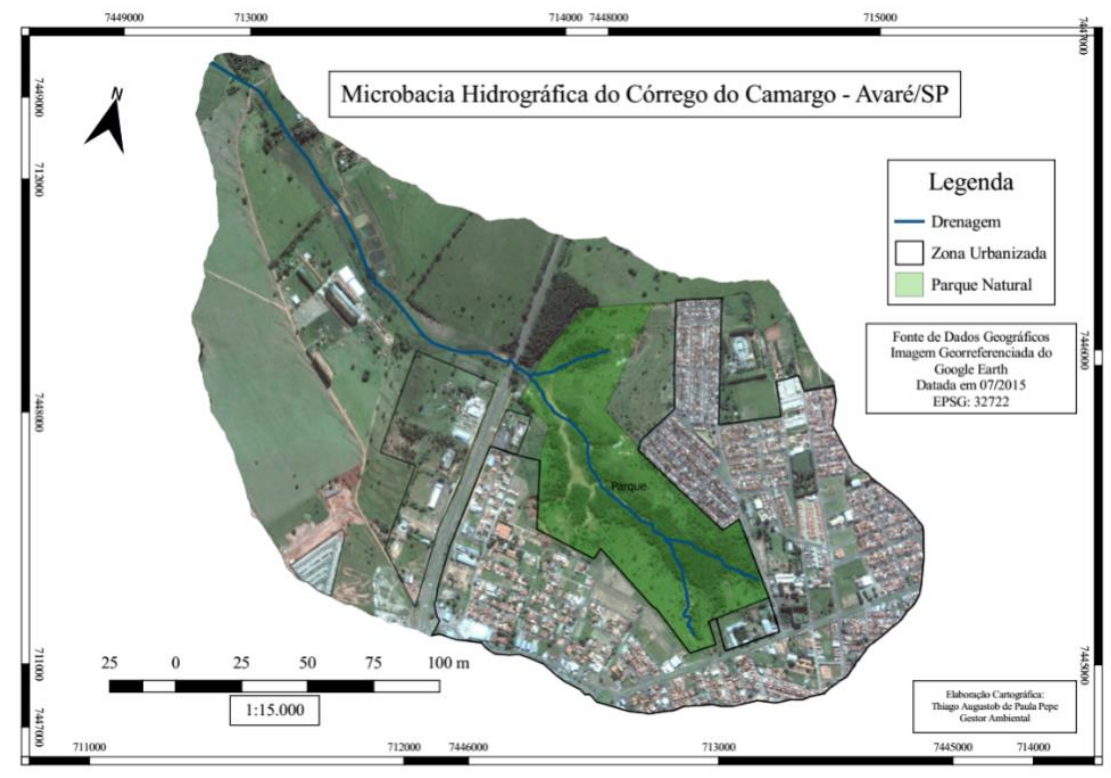

Figura 1: carta da microbacia do córrego do Camargo e do limite do Parque Terezinha de Freitas.

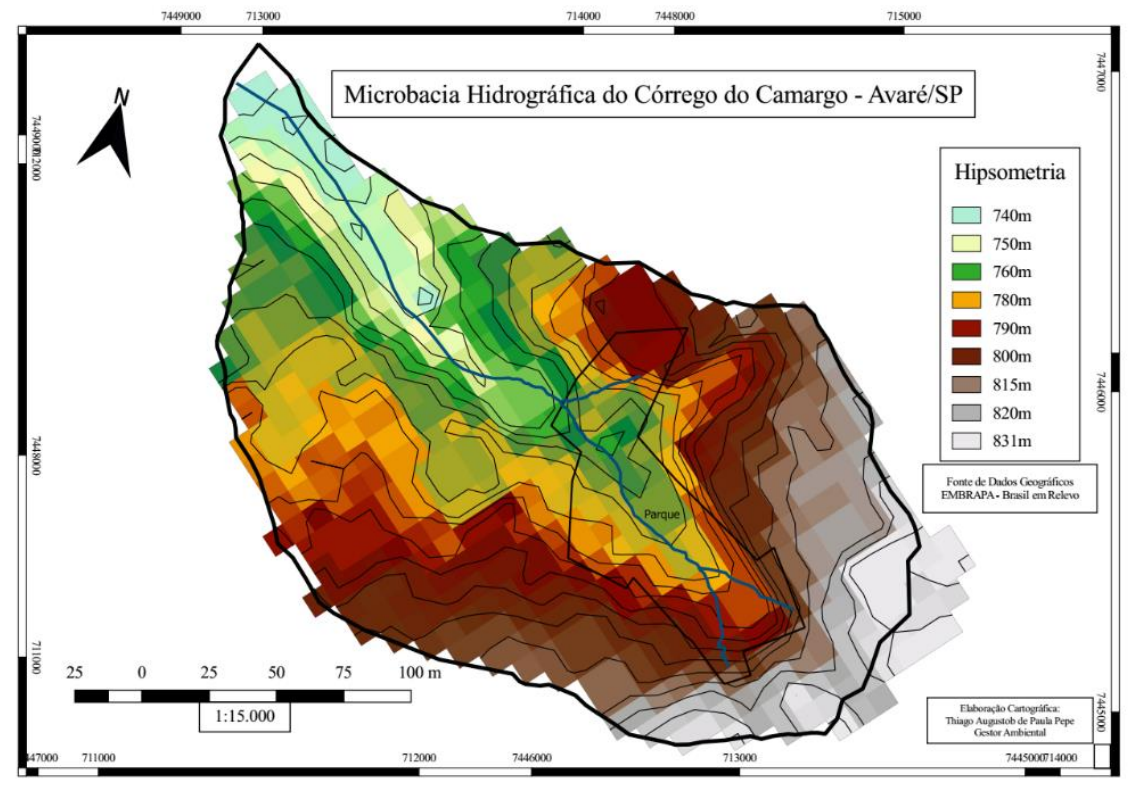


Figura 2: carta da microbacia do córrego do Camargo apresentando hipsometria.

\section{Metodologia}

Este trabalho foi desenvolvido em 7 etapas, a saber:

1 Etapa- Aquisição de imagens do software Google Earth Pro dos anos de 2004 e 2015;

2 Etapa - Elaboração de base cartográfica com a digitalização do mapa topográfico, assim como os canais de drenagens e estradas.

3 Etapa- Elaboração das castas de uso e ocupação do solo para os anos de estudo;

4 Etapa- Identificação das Feições Erosivas com base em três critérios: evidência de incisão no terreno, estágio evolutivo ativo ou reativado (presença de movimentação nas paredes), solo exposto e que estas feições não pudessem ser confundidas com outro tipo de processo e/ou fenômeno natural ou antrópico. As feições do tipo voçorocas foram delimitadas como feições individuais ou ainda como complexas em função das características geométricas e espaciais, como aquelas com múltiplas ramificações com dificuldade para serem individualizadas. Os sulcos e ravinas foram mapeados individualmente ou como concentração em função do número de feições em área.

5 Etapa- Trabalhos de campo para comprovação das feições identificadas nas imagens. Para a caracterização das feições com aplicação das planilhas de inventário de campo para as lineares e áreas afetadas, conforme apresentado em Dantas-Ferreira \& Pejon (2006).

6 Etapa - Elaboração dos mapas de inventários para os anos de 2004 e 2015 em escala 1:25.000.

7 Etapa- Análises e interpretação dos resultados.

\section{Resultados e Discussões}

A partir de dados geográficos EPSG:32722 foi elaborada a carta de uso e ocupação do solo da microbacia hidrográfica do córrego do Camargo referente ao ano de 2004 (Figura 3), com os seguintes componentes: a drenagem, os pontos de assoreamento, pontos de solo desnudo, cobertura vegetal, as zonas industrial e urbana, a área de atividade agropastoril e silvicultura e a área úmida. Relativo a este mesmo período, foi confeccionada também a carta chamada "Parque Ecológico Terezinha de Freitas - Avaré-SP", utilizandose imagem georeferenciada do Google Earth, na qual evidencia a presença de assoreamento do córrego do Camargo e de áreas com solo desnudo (indicativo de suscetibilidade à erosão) (Figura 4). 


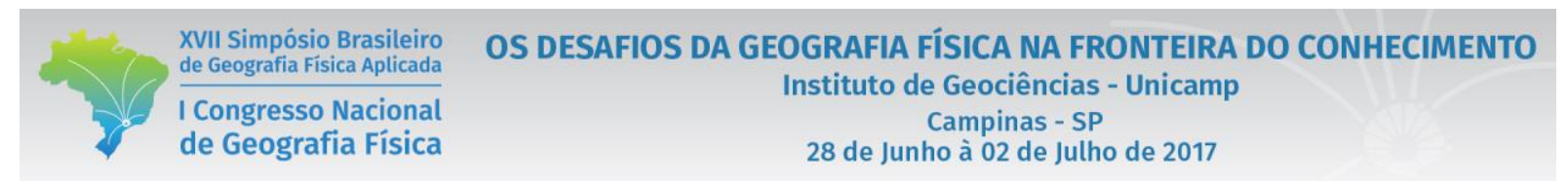

Observa-se que os processos erosivos não se restringem as zonas de cabeceiras ou marginais, mas possuem uma grande influência das zonas urbanas adjacentes. A suscetibilidade natural dosterrenos associados ao lançamento de águas pluviais sobre os terrenos desnudos caracterizam-se como os processos desencadeados para ocorrência de processos erosivos lineares mais graves.

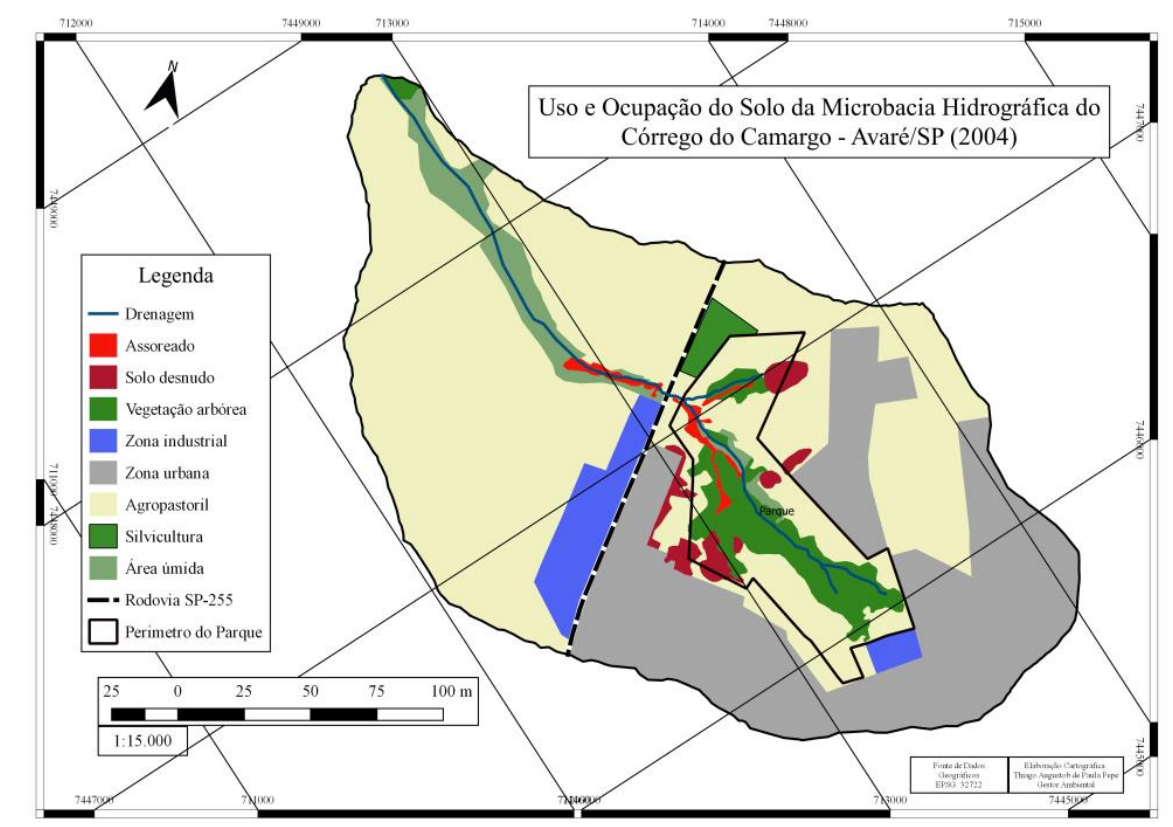

Figura 3: Carta de usoe ocupação do solo da microbacia hidrográfica do córrego do Camargo referente ao ano de 2004.

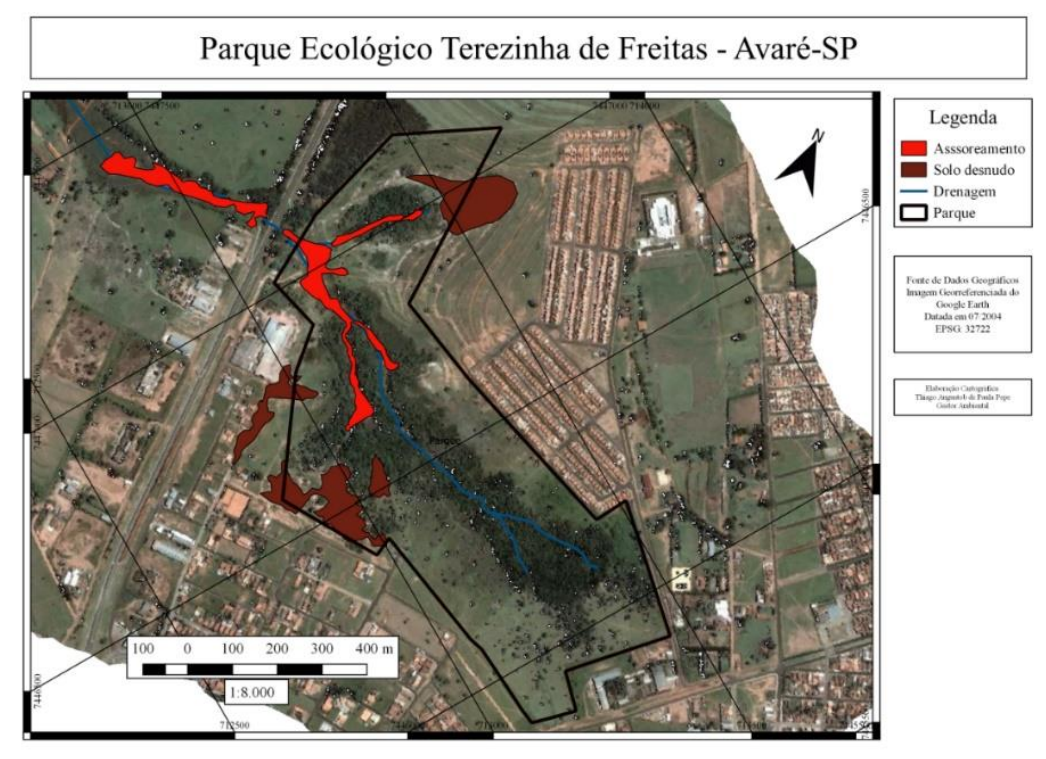

Figura 4: Carta "Parque Ecológico Terezinha de Freitas - Avaré-SP”, referente ao ano de 2004. 
De maneira mais detalhada, os dados de uso e ocupação do solo da microbacia hidrográfica do córrego do Camargo - Avaré/SP (2004) obtidos a partir da metodologia descrita apontam para os seguintes valores (em hectares): Bacia Hidrográfica: 412,98ha; Solo desnudo: 6,64ha; Vegetação arbórea: 19,80ha; Área urbana: 114,15ha; Área industrial: 15,90ha; Área úmida: 16,72ha; Agropastoril: 233,32ha; Silvicultura: 3,41ha (Figura 5).

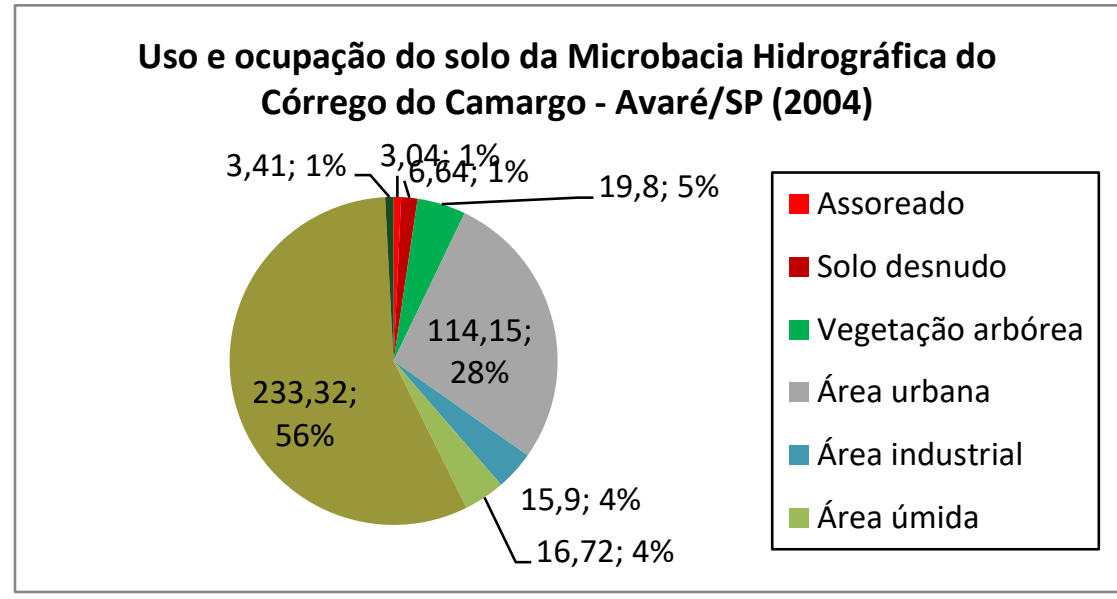

Figura 5: gráfico dos dados de uso e ocupação do solo da microbacia hidrográfica do córrego do Camargo Avaré/SP, referentes a 2004.

Tendo sido repetido o mesmo trabalho com as informações mais atuais, relativas ao ano de 2015, a segunda carta de uso e ocupação do solo da microbacia hidrográfica do córrego do Camargo (Figura 6) e a carta "Parque Ecológico Terezinha de Freitas - Avaré-SP" (Figura 7) evidenciam a presença da erosão, não existente no instrumento do ano de 2004.

Nos círculos em vermelho na figura 6, pode-se observar que existem voçorocas que estão restritas a área do parque e outras que já começam a atingir zonas urbanizadas. Estes locais passam a ser utilizados devidos a seu nível de degradação, como área de lançamento de resíduos sólidoso que provoca graves riscos de contaminação dos solos e das águas.

Em 2015, ainda sem qualquer projeto para recuperar ou controlar a erosão existente na Rua Lion, localizada no Jardim Europa II, a Prefeitura de Avaré resolveu adotar uma medida paliativa: criou barreiras físicas com entulho e placas de sinalização para evitar acidentes. Foram também construídos 2bacias de contenção, para minimizar os efeitos dos fluxos de água das galerias dos bairros que eram lançados para dentro das erosões.

Vários bairros do entorno foram afetados e com isso os valores de imóveis e terrenos próximos tiveram seus valores venais reduzidos. Atualmente a esquina entre as ruas Lion e Zurique foi totalmente erodida, 


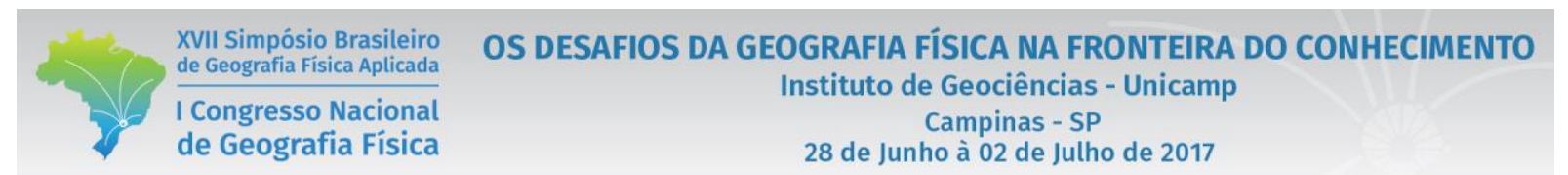

tubulações estão expostas, há canos quebrados e escombros. Por enquanto, nenhuma casa precisou ser interditada e ainda não há um prazo para uma solução definitiva.

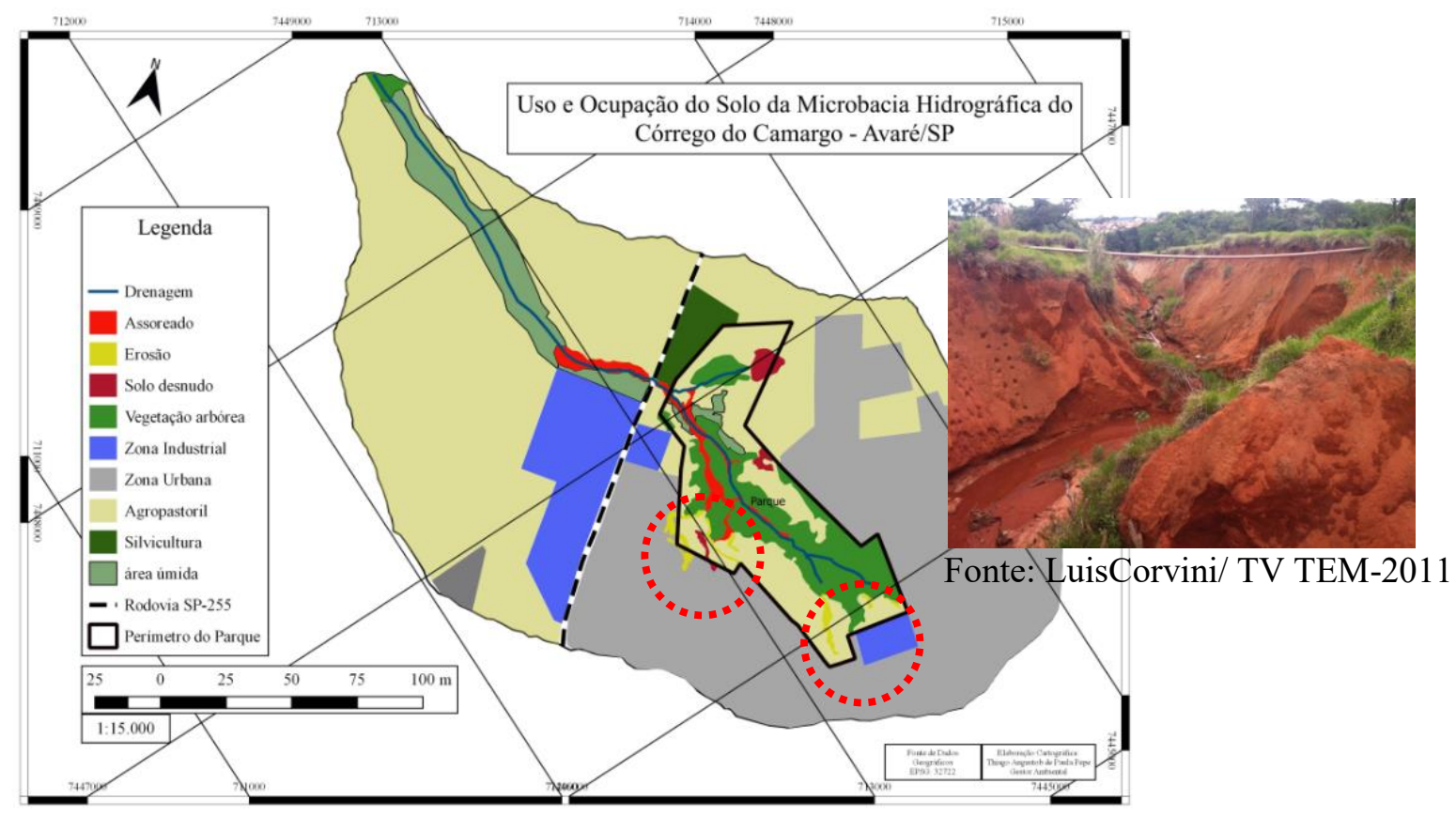

Figura 6: Carta de uso e ocupação do solo da microbaciahidrográfica do córrego do Camargo, referente ao ano de 2015.

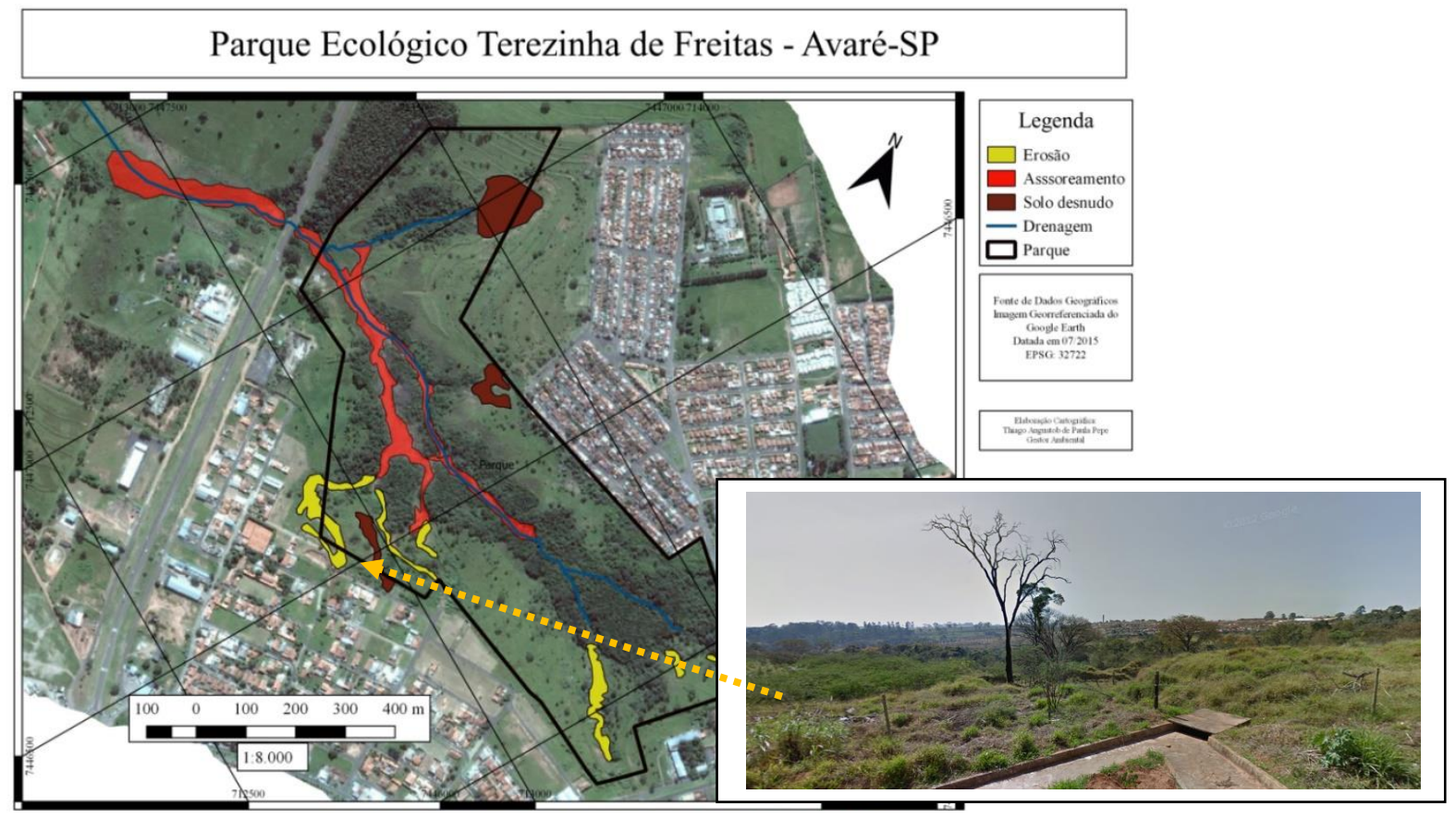

Figura 7: Carta “Parque Ecológico Terezinha de Freitas - Avaré-SP”, referente ao ano de 2015. 
Os dados de uso e ocupação do solo da microbacia hidrográfica do córrego do Camargo - Avaré/SP referentes ao ano de 2015 (Figura 8) apontam para os seguintes valores (em hectares): Bacia Hidrográfica: 412,98ha; Assoreamento: 4,77ha; Erosão: 2,15ha; Solo desnudo: 1,79ha; Vegetação arbórea: 21,88ha; Área urbana: 139,67ha; Área industrial: 27,01ha; Área úmida: 16,56ha; Agropastoril: 194,19ha; Silvicultura: 4,96ha.

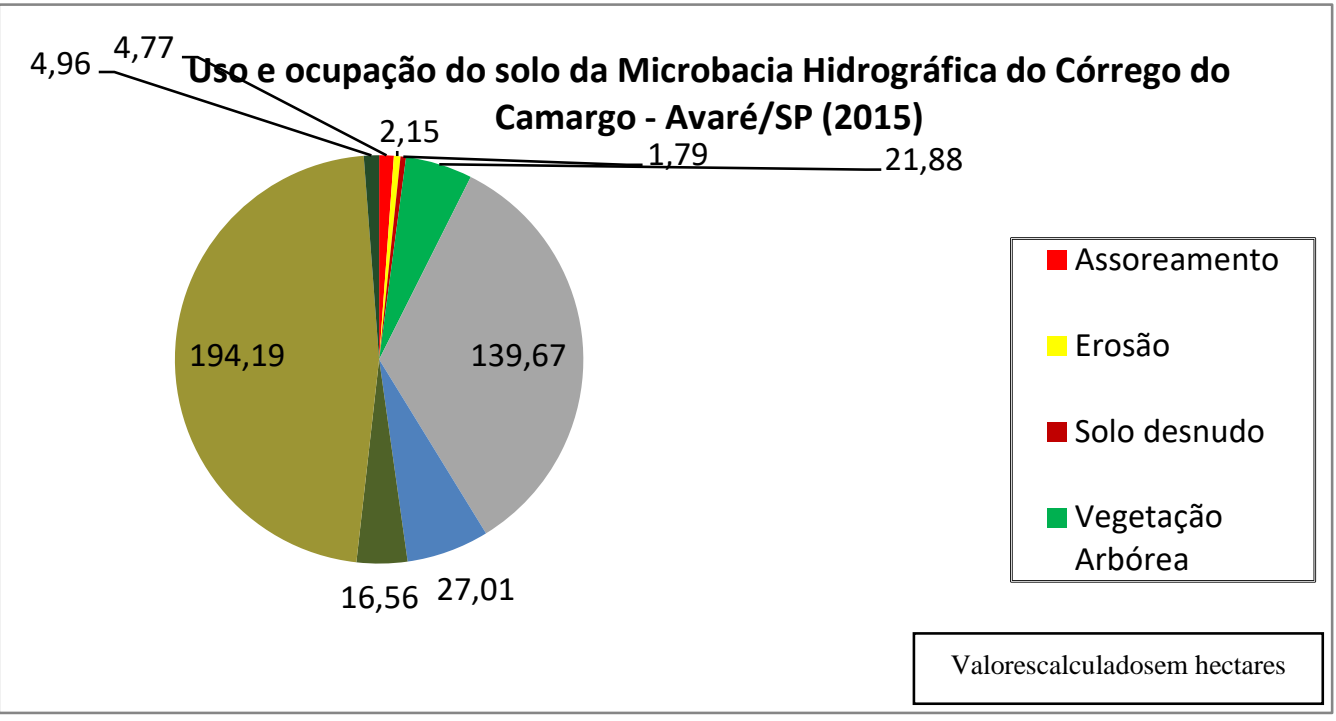

Figura 8: gráfico dos dados de uso e ocupação do solo da microbacia hidrográfica do córrego do Camargo Avaré/SP, referentes a 2015.

\section{Conclusões}

A partir da análise comparativa entre as informações presentes nas cartas chamadas "Parque Ecológico Terezinha de Freitas - Avaré-SP” dos anos de 2004 e 2015(Figuras 4 e 7, respectivamente), fica evidenciado em 12 anos o surgimentodos processos erosivos (destacado na cor amarela) na área de estudo, que passaram de zero para 2,15 hectares. A partir das análises, para as informações relativas ao uso e ocupação do solo do ano de 2004 e 2015 , as principais informações obtidas correspondem ao aumento da área urbana e da área industrial, juntas somavam 130,05 hectares em 2004(31,50\% da área da microbacia) e atualmente possuem mais de $40 \%$ desse total (166,68ha). Em termos percentuais, essas foram as áreas que mais ganharam espaço na microbacia em relação aos demais componentes analisados (assoreamento, vegetação, área úmida, solo desnudo, agropastoril e silvicultura).

Estes resultados corroboram, portanto,as considerações apontadas pelo Relatório Técnico do IPT ao evidenciar o aumento das áreas urbanizadas na microbacia estudada, que engloba a área do Parque Terezinha de Freitas. Nesse sentido, tem-se a necessidade de refletir sobre a importância da realização de estudos consistentes que embasem o zoneamento territorial urbano. Áreas como a que foi foco deste 
trabalho são comuns em diversos municípios brasileiros. Sugere-se que opoder público local, com atribuição de evitar e/ou solucionar problemas de erosões em área urbana, trabalhe com maior proximidade com a comunidade técnico-científica, diante do qual pode oferece meios para que seja evitado esse e outros tipos de ônus à população.

\section{Bibliografia}

ALMEIDA FILHO, G. S. Diagnóstico de processos erosivos lineares associados a eventos pluviosos no município de Bauru,SP. Universidade Estadual de Campinas. Campinas-SP. 2000.

AVARÉ. Lei Ordinária $\mathrm{N}^{\circ}$ 53, de 25 de abril de 2001. Cria o Parque Ecológico Água do Camargo Prof. ${ }^{\mathbf{a}}$

Terezinha Teixeira de Freitas e dá providências correlatas. Acesso
em: $<$ http://consulta.siscam.com.br/camaraavare/Documentos/Documento/100544>. Acesso em jan, 2017.

CEPAGRI. Clima dos Municípios Paulistas. Disponível em: $<$ http://www.cpa.unicamp.br/outrasinformacoes/clima_muni_052.html $>$. Acessoemjan, 2017.

Dantas-Ferreira,M.; Pejon,O (2006) Erosion inventory in the region of São Pedro and Barra Bonita cities, state of São Paulo, Brazil in 10th International Congress of the IAEG (International Association for Engineering Geology and the Environment). Nottingham.

Dantas-Ferreira, M (2008) Proposta de índice de processos erosivos acelerados a partir de levantamento e diagnóstico Geológico-Geotécnico de áreas degradadas. 447p. Tese de Doutorado - Escola de Engenharia de São Carlos, Universidade de São Paulo, São Carlos.

IBGE CIDADES. Disponível em:<http://cidades.ibge.gov.br/v3/cidades/municipio/3504503>. Acesso em jan, 2017.

Lewis, D. J., Tate, K.W. e Haper, J.M. (2000) Sediment delivery inventory and monitoring- a method for water quality management in rangeland watersheds. UC-DANR, publication 8014.Morgan, R. P. C. Erosión y conservacióndelsuelo. Madri: Ediciones Mundi-Prensa. 1996. 343p.

Morgan, R. P. C. (1996)Erosión y conservación del suelo. Ediciones Mundi-Prensa. Madrid. 343p.

RELATÓRIO TÉCNICO. Diagnóstico dos processos de erosão na área urbana do município de Avaré-SP”. Instituto de Pesquisas Tecnológicas do Estado de São Paulo - IPT. 2015. 